\title{
Government Management Innovation in the Age of Big Data*
}

\author{
Que Tianshu \\ East China University of Political Science and Law, Shanghai, China
}

\begin{abstract}
Both opportunities and challenges are currently faced by government management innovation in the age of "big data". Traditionally, relative studies view the management of governments as the effective means to improve governmental services, without really understanding the structural influence of big data and network technology on governmental mode of thinking. Against such backdrop, this paper tries to conduct critical analysis based upon traditional outcomes in this regard, trying to make full use of the function of big data technology. With these efforts, this paper contributes to the building of an interaction theory that could promote transparency of information and customization and segmentation of the policies. By constructing a mode in which management could be carried out based on the law of big data, by building an information management system in which balance could be achieved between responsibility and freedom, by promoting the rebalancing among public power, online civil society and civil rights, the innovation of governmental management would be achieved.
\end{abstract}

Keywords: big data, government management, data dictatorship, information, network society, public power

\section{Introduction}

With Internet developing, a variety of terminal equipment produced prodigious amounts of data, which means the age of big data coming. International Data Corporation (IDC) research reports: in 2011, the number of global data created and copied is 1.8ZB. IDC predicts, in 2020, the number of data around the world will be 35ZB (Rayport, 2011), however, the edition "Encyclopedia Britannica" printed in 2010 is less than 4G. Wall Street Journal treats big data, intelligent manufacturing, and wireless network revolution as three grand technological transformations, which may be enough to match the change of last century (Mills \& Ottino, 2012).

There is no standard definition of big data now. As is usually considered, it is non-structured data in large and diverse forms. Big data is usually associated with Hadoop, NoSQL, data analysis and data mining, data warehouse, business intelligence, and cloud computing. A research report conducted by Gartner suggested large data is information asset of large capacity, high speed, and diversification (Gartner, 2011). They need a new approach to improve the decision-making ability, insight, and process optimization. The definition of IBM and IDC is more representative, both of which think big data should meet the " $4 \mathrm{~V}$ ", three of which are Volume, Variety and Velocity. IBM identified the Fourth "V" is Veracity, but IDC identified the Fourth "V" is Value. Net-App thinks big data includes three elements "ABC", namely, Analytic, Bandwidth, and Content. Of course, regardless of various definitions, big data inevitably subverts the traditional way of data management, which brings revolutionary change in the data source, processing method, and thinking. Computer Turing Award

\footnotetext{
* Project Supported: any funding of the "Hua and Luo" comparative political research project.

Que Tianshu, assistant professor, East China University of Political Science and Law, Shanghai, China.

Correspondence concerning this article should be addressed to Room 201 (SE) Futian Stadium, 555 Longyuan Rd., Shanghai 201620, China.
} 
winner Jim (2009) put forward the fourth model of science research whose main characters are collaboration, networking, and data intensive (Holstead \& Redmond, 2009). Schoenberg and Kukye thought that big data relates to three major changes in thinking and interaction each other: analyze all the data associated with something rather than a small number of data samples; be willing to accept complicated data instead of the pursuit of accuracy; regardless of causality but search for the relationship between things (Schoenberg, 2013a; Kukye, 2012); big data reshapes our lives, work, and the ways of thinking, meaning the "information society" finally be worthy of its name (Schoenberg, 2013b). Big data indicates that the mankind society is stepping from the information age into the era of intelligence.

Government management innovation in the age of big data has emerged. The data analyzing team behind President Obama plays a crucial role in his re-election campaign, highlighting the new rules of electoral politics in the age of big data. In 2012 March, the federal government announced the launch of American "big data development project", which is located as an important national strategic. The United Nations launched "Global Pulse" project, using big data to promote global economic development. They make "sentiment analysis" for data of social networking sites and text information through natural language decryption software, which helps an area forecast unemployment, spending cuts, and disease outbreaks. In 2010 July, the British Cameron government launched a new agenda in the foundation of the open data movement, which advocated more rights from the central to local, from the local to the community, from politicians to the public so as to establish a bigger, stronger, and better society (Tu, 2012, p. 311). Big data will ensure public information open and transparent. At the same time, open data inevitably affects the government management innovation.

Based upon such critical analysis, firstly, this paper will provide three research perspectives of the governmental management in social management, which are respectively the perspective of non-binding utopia, the perspective of high-pressure leviathan, as well as the neutral perspective from which real and virtual society could achieve positive interaction. After then, this paper will introduce the innovation and challenges of government management innovation in the age of big data. The innovation and challenges will inevitably update government management, making it more structured and scientific. And a new management mode, in which management could be carried out based on the grasping of the law of big data, will emerge, and a more effective information management system, in which responsibility and information will be attached equal importance, will be built. This management mode promotes the positive interaction between public power and civil rights in social network.

\section{Three Perspectives on the Study of Government Network Management}

Big data means great wealth to especially developing countries (Kshetri, 2014). As an emerging industry, it could bring enormous opportunities and challenges. In China, however, academic circles' studies in this regard are still in the primary stage. Actually, big data represents an important technical field in data science, while most scholars in China do not have enough knowledge base of big data. Against such backdrop, the practical value of big data cannot be made full use of by specific technical practices.

Due to the insufficient understanding on big data, some scholars study it just from a unidirectional instrumentalism perspective. For instance, a scholar pointed out that in the organizational structure, big data technology could transform the traditional structure to governance of pluralism, transform close structure to open structure, and transform bureaucracy hierarchies to flattened structure (Wang, 2014). However, due to the close relationship between big data technology and network technology, such perspective ignores that network 
technology might turn to an oppressive instrument of domination under government intervention. In fact, scholars in other countries have already made it clearly that online society in the 21 st century will create more opportunities, hence, what government management should do is to gather these challenges together instead of creating more challenges (Prasad, 2012). Neutrality of the data will not only make it a helpful public good, but also shape it a profit-making carrier even a rent-seeking object. As to the role of big data technology in government governance, mode of thinking of most scholars in China is still outdated, viewing the big data technology as a necessary instrument to achieve and optimize government services (Yang, 2014; Pan, 2014). Therefore, studies on big data in previous documents have not only looked down upon the role of network technology as a foundational framework, but also ignored the influence of great changes carried by big data technology on government management. Besides, still some scholars have mentioned about the active process of big data in government governance and social governance (Pan, 2014; Hu, 2014). But these researches have not pointed out the detail content of the dynamic mode. Guided by such perspective, studies on big data governance might not be deep enough, ignoring that the dynamics of big data is helpful in fixing the blind spots of governmental governance, not to mention carrying out depth studies on the revolution of government management against the age of big data.

Governments of various countries have taken some methods in this field, which attracts the attention of academic circles to the influence of big data governance on government management. Generally speaking, three perspectives of studying the government management in online social management in academic circles are as follows:

\section{The Anarchism in Government Network Management: The Utopia of Freedom}

Restricted by the times, the early Internet researchers pay more attention to the advantages of network. The Internet makes the cultural, politics out of the "center". The network society is always associated with open, freedom, equality, and sharing together, in which the traditional discourse hegemony and centralization are subverted. In the study of bureaucratic rule, Berson and Shujiro (1988, p. 7) thought that the development of computer technology deepens people for freedom and democracy, making the mass energy burst out (Berson \& Shujiro, 1988, p. 7). As a representative of the scholars on the network management, Barlow thought cyberspace makes a society that is of difference from the reality - freedom but without confusion, management but without government, consensus but without privilege (Lessig, 2004, p. 4). Negroponte (1997, p. 274) pointed out: neither legal nor bomb can make politicians control the network. The message can be sent out by one way or the other. Yuan (2006) also thought: the Internet gives people the rights of equal communication and expressions, which makes the social culture of a diversified development. Providing free interactive political hegemony, economic benefits for the public, Internet becomes a challenge to the social mainstream culture authority.

\section{Levitan in Social Network Management}

This perspective thoughts filtering, network database, electronic monitoring, and site blocked technology can strengthen the control of power so as to create a Levitan of social network management. Both government and large enterprise groups intend to control the internet. As Hiller (2001, p. 289) pointed out, the Internet is not a new kingdom detached from the real world. On the contrary, the Internet is close to the real world. The Internet in fact is the most wonderful political tool in the age of globalization. Post (2001, pp. 93-98) believed that any communication between people and people, people and institutions will leave traces in the database in the age of big data. Private activity becomes a kind of public activities. The database can revise us without eyes 
but through the cyber space more accurately. In Fantine's opinion, in the authoritarian regimes, the Internet was a contradictory existence, which not only threatens but also strengthens government's control of information and society (Fantine, 2004, pp. 3-5).

The Interaction Between the Government Behavior in the Network Society and Real Social Management

The research views the Internet as a neutral tool. Internet is embedded in the concrete structure of the society and the political culture, in which government behavior pattern is strengthened. As Keohane and Nye (2002, pp. 258-260) thought the classical political issues on who rules, how to rule and whoes benefits not only relate with the traditional physical space but also relate with network space. Information does not flow in a vacuum, but in political space (Keohane \& Nye, 2002, pp. 258-260). Sheldon (2013) discussed the meaning of internet political ecological system and the components. He thought that the internet political ecosystem is an ecological system treating information as the core. Members in the system generate information, through which they communicate each other, ultimately complex self-organizing and self-adjustment function made. The electronic government plays guiding role (Starr, 2010). Xiao (2009) thought information technology not only breeds a great opportunity to digital democracy but also faces realistic risks sliding into "digital Leviathan". Only by the way of citizens, civil society, and constitutional democracy system can inhibit the single state monitoring system expansion to overcome "digital Leviathan". The rise of the network society management is not sudden. But it has accumulated profound theoretical accumulation and practice such as multicenter governance theory, deliberative democratic theory, and public governance theory.

The three perspectives mentioned above in essence reflect different dimensions of the interaction between network information technology and public power. In spite of limitations, they are also enlightening. Firstly, the perspective of anarchism in government network management has already disappeared, because the information can be fully got today. No matter to a country, or an enterprise, or even individuals, there is a widespread awareness that trace of their online activities is valuable. Online activities out of control are unlikely to take place because of the security control on data and the spreading of the big data technology. Secondly, the leviathan perspective in social network management calls excessive control over Internet, undermining the innovation advantage and vitality of Internet related industries including big data industries. Therefore, this perspective fails to recognize the dynamics of continuity of online society. Comparatively speaking, the neutral perspective provides a compromise. To some extent, it prevents the binary opposition between the country and the society led by emerging technologies such as big data from happening.

In the process of online social management, big data technology continuously promotes changes and revolutionary innovation in traditional government management. Prior to the receiving attention of big data technology, governments make changes only when receive passive feedback. Currently, however, it has no other choice but to take the initiative to adjust itself to adapt to the network environment under present-day circumstance. Then, a conclusion can be made that big data brings both innovation requires but also daunting challenges to government management.

\section{The Mode and Challenge of Realizing Government Management Innovation in the Age of Big Data}

\section{The Mode of Realizing Government Management Innovation in the Age of Big Data}

The transparency of information. Revolution of information creates a new political trust, in which the 
transparency of information is becoming a kind of right assets (Holdren, 2010). The data will be a good opportunity for the government to achieve the transparency of information. The data of government departments are easy to get, which can improve their work efficiency. In 2009 March, Obama appointed the first Chief Information Officer in history. Then the federal government open data portal Data. gov appears on line. A "planning the digital future" report in 2010 said "every agency and department of the federal government need to make a data strategy to establish an open and transparent government, in which citizens can participate and cooperation can be possible" (Holdren, 2010).

Forecast public demands. It is the core of big data to apply the mathematical algorithm to the data to predict the possibility of things. The government can analyze the data to response to the public timely. Farrel (2013) pointed out: if the individual activity on the Internet can be systematically captured, we can infer for the first time in history informal communication and opinions between people in the Internet. Big data reflects the public opinions. Mass data on the Internet record thoughts, behaviors and emotions of the public, which is the combination of the reality and network space, containing rich regular information (Wu, 2013).

The policy based on population subdivision. The public department should provide equal services for all citizens. But if there is not enough data to understand public demands, the equalization of the service supply would not be possible. The McKinsey study found that, service can be supplied according to the data of individual or a certain group, which can improve the efficiency, effectiveness, and citizen satisfaction. Fortunately, big data provides an opportunity to realize it. For example, through analysis of massive historical, the German Labor Bureau adjusts government's welfare for the unemployed, reducing government spending and improving user's satisfaction (Guo, 2013, p. 40).

\section{The Challenge of Realizing Government Management Innovation in the Age of Big Data}

Data dictatorship. Using big data, Amazon checks our shopping habits, Google checks our webpage browsing habits, Twitter hacks our information, and Face book seems to know all, including our social relationship. Government uses big data not less than private enterprises. Washington Post disclosures, in 2010, the number of e-mails, phones, and other communication records intercepted by USA NSA every day is up to 1.7 billion (Schoenberg, 2013b). Big data threaten our privacy and freedom, which are the foundation of modern society. It also aggravated an old threat that we rely too much on data, but the data is not reliable as what we imagine. Digital memory created by big data not only supports the control of hierarchical organization and society but also seeks for their own support so as to consolidate and deepen unequal information power distribution (Schoenberg, 2013a). In a word, big data may produce "data dictatorship".

Privacy was abused to preemptive punishment. Value of Big data is no longer simple basic use, but is more used twice. A lot of data is not intended for other uses when in the collection, but eventually many innovative uses occur. Big data makes the community lose the ability to forget, and perfect memory instead. Our past as a tattoo inscribed on our digital skin (Schoenberg, 2013a). In fact, American Department of Homeland Security is developing a set of future behavior detection technology security technology. They can find potential terrorists by monitoring personal characteristic and individual behavior (Schoenberg, 2013b). In particular, in the transition from small data to big data, data quality may be poor, not objective, misleading, or not quantified. We do not have idea inaccurate forecast will damage social system order.

Digital divide. Digital memory deepens the divide between the information rich and the information poor, which further enhances the power tilt. Digital memory has three characteristics: accessibility, persistence, and 
comprehensive. Business or government might use the information to achieve information superiority. We can not see reciprocity information, but the information power from powerless to the power (Schoenberg, 2013a). The reason of digital divide is the differences among information collection, search and analysis, which will form an accumulative difference.

Institution. In the age of big data, the institution with purpose of protecting privacy policy will fail. It can be seen as a proof of Austrian's word "culture lag", scientific discovery or invention first, the backward adaptation culture can be often the social organization and ideology (Ogburn, 1989, pp. 268-269). Risk society theorists Rush (2002) thought: the institution using technology to avoid risks and dangers may involve new risk and lead to a larger scale degree of disorder even complete collapse. So social risks big data brings are huge.

\section{The Ways of Government Management Innovation in the Age of Big Data}

\section{Management Based on Data: Provide the Wise Public Service}

In the age of big data, the government will focus on data management, as shown in Figure 1:

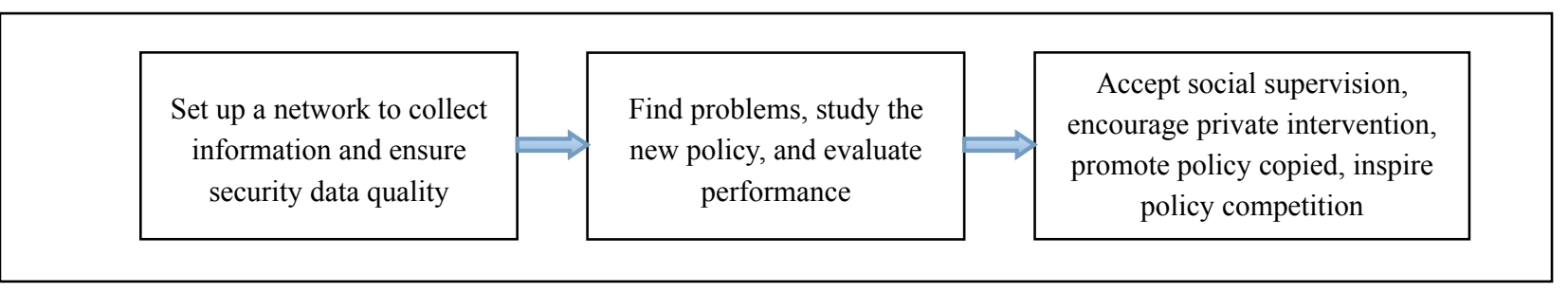

Figure 1. Government management based on data.

Change from information collector to information analysts. In the age of big data, the collection, management, and analysis of data are becoming more and more important. Though data of one year, one area does not see too many tricks, with the cross-regional and year, more and more groups' behavior characteristics will present order, correlation and stability and more rules will appear ( $\mathrm{Tu}, 2012$, pp. 67-70). Through the analysis of massive data, government can timely understand the public demands to improve the policy response so as to supply good public services.

Change from information claimants to information offer. In the age of big data, data can be automatically integrated on the internet. Using data technology tools to analyze the public browsing preference, service application, and online reviews, the government provides personalized service for the public. The main target of data open website "data. gov" set up by Obama government is to open information to inspire more innovations (Tu, 2012, p. 219). Similarly, in 2010, British Prime Minister Cameron proposed a concept "Right to Data", which thought right to data is a basic right in the age of big data. He also promised every citizen had the right. The labor department and business department in Britain announced a new project to implement the data right, My Data, which ensured personal right to data.

The government decision is from the prediction to real and accurate record. Firstly, social management information is published in time. For example, the data pulsation of United Nations emphasizes the real-time data. It makes the prediction by analyzing the real-time data to force the government decision changes from the prediction to real and accurate record. Secondly, more accurate information for decision making is needed. Big data is not random data analysis, but the full data, namely, "sample = populations" (Schoenberg, 2013a). In state of New Jersey, the introduction of INRIX (INRIX is a global SaaS and DaaS company which provides a variety of Internet services and mobile applications pertaining to road traffic and 
driver services.) data traffic management system, which is of accuracy and of broad coverage can reduce travel time and cost.

Construction of the responsible and freed information management system. In the age of big data, it needs to take more responsibility for privacy data management institutions to protect privacy information. Schoenberg put forward three strategies, including privacy preserving transformation from individual permission to data users (Schoenberg, 2013a). When using prediction analysis, individual motivation is needed to consider. Fighting against the data monopoly will be the basic of data management effectively (Schoenberg, 2013b). At the same time, he also put forward the concept of "Internet forgotten movement" in order to protect the right of privacy and data security (Schoenberg, 2013b). These measures all emphasize on both responsibility and freedom, which are also social network management development direction in the age of big data.

Rebalance public power, network citizen society and citizen rights. Since the birth of the network society, there always existed balance-imbalance-balance interaction among public power, network citizen society, and citizen rights. Balance between civil society and state is the ideal harmonious society. Civil society is not only an important bridge between the government and the citizen, but also a powerful source and an important factor of influencing the government decision-making and government reform (Narayan \& Liu, 2008, p. 95). Information technology is a kind of social right tools, which reduces the influence of population pressure on the individual. Through interaction, users will choose important problems they think rather than the media think important to become a part of the public agenda (Wang, 2006). The collective movements on the internet contribute to overcoming control by the public power. For example, open data movement has penetrated into political, cultural, social, and other aspects, creating the motions and the slogans of open political, open government, open media, open city, and so on. As a result, 50 governments participate in the "open government union", whose slogan is "Using format can be reused to publish high quality information, including the original data timely to the whole society" ( $\mathrm{Tu}, 2012$, p. 279), which reflects rebalance public power, network citizen society and citizen rights.

\section{Conclusion}

Based on the theory of government behavior and big data theory, this paper analyzes the mode and challenge of realizing government management innovation in the age of big data. In the age of big data, the following measures benefit to realize the government administrative innovation: applying the "management based on data" method, constructing the information management system on a responsible and liberal basis, and rebalancing the public power, internet civil society, and citizen rights. As an exploratory research, it helps us to understand the significance of government management innovation in the age of big data. But what needs to point out are: First, big data technology itself is not mature. The relevant technology and application in the field of social management is relatively less. So the conclusion of the paper needs further inspection and correction. Second, for China, it will be a gradual process to realize government management innovation in the age of big data. It requires government, industry, and academia work together, which is our next research direction.

\section{References}

Berson, Y., \& Shujiro, Y. (1988). Bureaucratic rule. Beijing: National Press.

Fantine, J. (2004). The construction of virtual government: Information technology and innovation. Beijing: People University of China Press. 
Farrel, H. (2013). The influence of Internet on political. Foreign Theoretical Trends, 1, 259-261.

Gartner. (2011). Big data in little New Zealand. Retrieved from http://itbrief.co.nz/news/big-data-in-little-new-zealand/124372/

Guo, X. (2013). The data. Beijing: Tsinghua University Press.

Hiller, D. (2001). Digital capitalism. Nanchang: Jiangxi People's Press.

Holdren, $\quad$ J. $\quad$ P. $\quad$ (2010). Designing a digital future. $\quad$ Retrieved from http://www.whitehouse.gov/sites/default/files/micros-ites/ostp/pcast/nitrd/report-2010.pdf

Holstead \& Redmond. (2009). The second media time. Athens: Mpenou Publications.

Hu, H. B. (2014). The government and politics in the Internet. Administration, 4, 32-41.

Jim, G. (2009). On science: A transformed scientific method. Based on the transcript of a talk given by Jim Gray to the NRC-CSTB1 in Mountain View, CA, on January 11, 2007. Retrieved from http://research.microsoft.com/en-us/collaboration/fourthparadigm/4th_paradigm_book_jim_gray_transcript.pdf

Keohane, R., \& Nye, J. (2002). Power and interdependence. Beijing: Peking University Press.

Kshetri, N. (2014).The emerging role of big data in key development issues: Opportunities, challenges, and concerns. Big Data \& Society, 3, 1-20.

Kukye, T. (2012). What is big data? WA: Microsoft Research.

Lessig, L. (2004). Code. Beijing: Zhong Xin Press.

Mills, M. P., \& Ottino, J. M. (2012). Technological change will lead to new economic prosperity. Retrieved from http://www.cn.wsj.com/gb/20120222/opn074317. asp

Narayan, K., \& Liu, M. (2008). The transformation of the development of civil society and governance: The experience of India. Beijing: Central Compilation and Translation Press (in Chinese).

Negroponte, N. (1997). Digital life. Haikou: Hainan University Press.

Ogburn, W. F. (1989). Social change-On the culture and the congenital essence. Hangzhou: Zhejiang People's Press (in Chinese).

Pan, H. (2014). The coming data revolution and how it change the government, business and our life. Guilin: Guangxi Normal University Press.

Prasad, K. (2012). E-governance policy for modernizing government through digital democracy in India. Journal of Information Policy, 5, 183-203.

Post, M. (2001). The second media age. Nanjing: Nanjing University Press.

Rayport, J. F. (2011). What big data needs: A code of ethical practices. Retrieved from $\mathrm{http}: / / w w w . t e c h n o l o g y r e v i e w . c o m / n e w s / 424104 /$ what-big-data-needs-a-code-of-ethical-practices/

Rush, S. (2002). Risk society and risk culture. Marx Doctrine and Reality, 5, 25-42.

Schoenberg, M. (2013a). The age of big data. Hangzhou: Zhejiang People's Press (in Chinese).

Schoenberg, M. (2013b). Remove the data the way of choice. Hangzhou: Zhejiang people's Press (in Chinese).

Sheldon, T. (2013). Constructing the virtual government. Information, 36, 66-83.

Starr, H. (2010). Structure and interaction mechanism research in internet political ecosystem. The Study of Political Science, 5(3), 25-38.

Tu, Z. (2012). Big data: The data revolution is coming, and how it changed the government, business and life. Guilin: Guangxi Normal University Press (in Chinese).

Wang, S. (2006). Chinese public policy agenda setting models. Chinese Social Science (in Chinese), 6(5), 34-51.

Wang, X. M. (2014). The opportunities and challenges at big data time. Administration, 3, 32-45.

$\mathrm{Wu}$, H. (2013). Opportunities and challenges in the age of big data. Qiushi (in Chinese), 4, 24-29.

Xiao, B. (2009). Information technology of double side and non-equilibrium in the governance of the country. Academic Studies (in Chinese), 2(11), 25-30.

Yang, D. M. (2014). Risk society and the culture and risk. Marxism \& Reality, 3, 11-21.

Yuan, F. (2006). The government and politics of network society-The political effects of network technology in modern society. Beijing: Peking University Press. 